\title{
Article \\ The Influence of COVID-19 on Women's Perceptions of Work-Family Conflict in Singapore
}

\author{
Loo Seng Neo, Jean Yi Colette Tan * and Tierra Wan Yi Chew *
}

RySense Ltd., 331 North Bridge Road, \#13-01 Odeon Towers, Singapore 188720, Singapore; looseng.neo@rysense.sg

* Correspondence: colette.tan@rysense.sg (J.Y.C.T.); tierra.chew@rysense.sg (T.W.Y.C.)

Citation: Neo, Loo Seng, Jean Yi Colette Tan, and Tierra Wan Yi Chew. 2022. The Influence of COVID-19 on Women's Perceptions of Work-Family Conflict in Singapore. Social Sciences 11: 73. https://doi.org/10.3390/ socsci11020073

Academic Editors: Gayle Kaufman and Nigel Parton

Received: 18 November 2021

Accepted: 5 January 2022

Published: 14 February 2022

Publisher's Note: MDPI stays neutral with regard to jurisdictional claims in published maps and institutional affiliations.

Copyright: (C) 2022 by the authors. Licensee MDPI, Basel, Switzerland. This article is an open access article distributed under the terms and conditions of the Creative Commons Attribution (CC BY) license (https:// creativecommons.org/licenses/by/ $4.0 /)$.

\begin{abstract}
The COVID-19 pandemic has facilitated a shift in working arrangements. Work from home may blur work and family boundaries, with potential deleterious influence on Work-Family conflict levels. This is especially so for women, who have traditionally been associated with a greater share of homecare and family duties. Using a sample of 754 married, working mothers in Singapore, this study seeks to examine the conflicting roles of women in Singapore during COVID-19 and their consequences on Work-Family conflict. Results show that the negative impacts of COVID-19 increased Work-Family conflict levels. Additionally, factors such as work occupational commitment, work role overload, parental demands, and family support are found to be key predictors for WorkFamily conflict during COVID-19. Implications are then discussed, and the findings can inform companies and governmental institutions on strategies to reduce Work-Family conflict levels.
\end{abstract}

Keywords: COVID-19; Work-Family conflict; women; Singapore

\section{Introduction}

The spread of COVID-19 across the world has disrupted the order of daily lives. The spotlight was turned onto healthcare systems as many countries struggled to deal with variants of the disease, waves of infections, and deaths. Globally, there was economic and social turmoil that was associated with increases in suicide rates and mental health issues (McIntyre and Lee 2020; Sher 2020; Sakamoto et al. 2021). As countries battled with the strain on their healthcare systems, there was little focus on how the pandemic has impacted family relationships, especially for women, who have been doing more unpaid care work than men prior to the pandemic (see Power 2020). Emerging research (e.g., Power 2020) also suggested that the burden of unpaid care work is now greater during the current pandemic.

Work and family domains have been the main pillars for most individuals in every society (Ahmad and Skitmore 2003; Lee and Lee 2021). As a result, they may inadvertently serve as the primary source of support or stress in times of crisis. While it is vital to embrace the positive elements of these domains, it is equally, if not more important to understand the stress they may induce. For example, Fisher et al. (2020) highlighted the risks that the pandemic poses to work and family domains, including unemployment and the lack of childcare support for those with children. However, recent studies that explored the impacts of the pandemic have centered largely around Western contexts, leaving a gap in the literature for Asian contexts, specifically in Singapore. This study thus seeks to fill the gap by examining Work-Family conflict (WFC) in Singapore during COVID-19.

\subsection{Work-Family Conflict (WFC) and COVID-19}

WFC is a type of inter-role conflict in which one's work and family roles interfere with each other, and in some respects, are mutually incompatible (Kahn et al. 1964; Greenhaus and Beutell 1985). These roles were often seen as competing demands for time and effort, resulting in conflict. A wealth of literature found negative outcomes of WFC such as lower life satisfaction (Bedeian et al. 1988), job satisfaction (Bacharach et al. 1991; Adams et al. 1996; 
Wang et al. 2010), marital satisfaction (Aryee 1992; Galovan et al. 2010), and family satisfaction (Carlson et al. 2000; Kim and Ling 2001), and WFC is a significant predictor for burnout (Aryee 1993), depression (Guille et al. 2017), and emotional exhaustion (Ahmad 2010). In addition, Jones et al. (2020) found that the perception of successfully integrating work and family life was strongly associated with family satisfaction.

With the emergence of COVID-19, national measures were introduced and working arrangements transformed almost immediately to working from home (Acar 2020; Forbes et al. 2020). In 2020 and 2021, spikes in COVID-19 infections prompted many countries to go into lockdown or a state of emergency. For example, the United Kingdom had national lockdowns in March and November 2020, as well as in January 2021 (Chung et al. 2021). The reduction in the workforce's physical presence in office spaces, a common locus of interaction, became one of the critical levers in managing the virus transmission (Ingram et al. 2021).

In Singapore, authorities put in place a month-long "Circuit Breaker" in April 2020 (Chen et al. 2020), grounding most business and social activities that were not considered "essential services", and announced work from home as the default (Chen et al. 2020). Since then, workplaces have been encouraged as much as possible to allow their employees to work from home. Chung et al. (2020) studied the effects of this transition during the "Circuit Breaker" and found the work-life balance of Singaporean mothers to be generally lower than that of fathers. Laumer and Maier (2021) discussed the potential distractions from family members, whereby the physical boundaries separating work and home activities were blurred (Rau and Hyland 2002). Working from home may also result in employees feeling isolated (Laumer and Maier 2021) or lacking sufficient professional and social support due to the lack of face-to-face interactions (Weinert et al. 2015). Working from home was also linked to increased job stress (Irawanto et al. 2021). However, given the prolonged battle against the pandemic, working from home is a fixture that will persist even into the post-pandemic era (Baert et al. 2020). Hence, it is important to start examining and tracking WFC in times of COVID-19.

\subsubsection{Work-Family Conflict (WFC) and Work and Family Factors}

WFC levels have been suggested to be higher for women than men (Voydanoff 2005; Kaufman and Taniguchi 2019), suggesting that while job and career opportunities for women have increased significantly over the decades (Sandberg et al. 2012), they were also likely to experience more WFC. Women have had to manage their professional career endeavors and family commitments; even though men have been more involved in the family setting (Goldscheider et al. 2015), women continue to shoulder a greater share of caregiving and childcare duties than men (González et al. 2009; Menniti et al. 2015). With changes in childcare and work arrangements brought about by the pandemic, women in the workforce were found to be disproportionately impacted by COVID-19 (Power 2020; Chung et al. 2021), which could exacerbate the guilt and WFC levels that were observed in studies (Haque 2000; Foley et al. 2005; Nasurdin and Hsia 2008; McLellan and Uys 2009).

Over the last couple of decades, Aryee (1992) and Kim and Ling (2001) have studied WFC among women in Singapore and identified work effects on the spousal, housework, and parental fronts. Research in the domain had since recognized that WFC can occur in both directions, where family roles can interfere with work roles, and work roles can interfere with family roles (Netemeyer et al. 1996; Frone et al. 1997). Huffman et al. (2014) distinguished between demands from work sources as resulting in work interfering with family (WIF) conflict and demands from family sources as resulting in family interfering with family (FIW) conflict. By identifying the type of WFC one experiences, relevant interventions can therefore be introduced to tackle the different factors associated with it (Byron 2005). Many work and family factors have been studied in the WFC literature. Michel et al. (2011) conducted a meta-analysis of various constructs that were examined across 142 studies, with work factors that spanned from role stressors (e.g., work role overload, work time demands) to work characteristics (e.g., job tenure, job autonomy), and 
family factors that ranged from role stressors (e.g., parental demands), family characteristics (e.g., family climate), to social support (e.g., family, spousal support). Relevant work and family factors were reviewed and explored in this study. It is important to note that studies examining these factors have found certain associations with WIF, FIW, and WFC (both WIF and FIW), and in some instances, no direction of conflict was defined.

\subsubsection{Work Factors}

Work occupational commitment is defined as a willingness to commit personal resources to assure success in or to develop the occupation role (Amatea et al. 1986). It was highly associated with salience to a career or work role, whereby conflict was induced when this salience was threatened (Aryee 1992; Carlson et al. 2000; Nasurdin and Hsia 2008). Work occupational commitment was included in this study due to its significance as a predictor for conflict between work and family. Lee and Lee (2021) found that an excessive commitment dedicated to work or the organization would encroach into the family domain, making it more difficult for one to perform in their family role, thus resulting in greater conflict levels. Luk and Shaffer (2005) also reported greater WIF levels for those who committed more time and resources to work.

Multiple studies have also found that work role overload contributed to conflict between work and family. Work role overload occurs when role expectations at work exceed the availability of time and resources needed to complete assigned responsibilities (Bacharach et al. 1991). Role overload becomes a stressor when an employee feels overwhelmed with the amount of tasks that they have to complete in a period of time (Fu and Shaffer 2001; Cardenas et al. 2004). For example, Nasurdin and O'Driscoll (2012) studied work role overload in Malaysia and New Zealand and found that it significantly increased WIF levels.

The value of work and work arrangements has changed in pandemic times. As such, it is necessary to study the effects of work commitment and work role overload on WFC in the COVID-19 situation.

\subsubsection{Family Factors}

Parental demands refer to both the number of children of working parents, as well as their children's ages. Bedeian et al. (1988) classified parental demands into five levels, where respondents with one or more children under the age of 6 were considered to have the highest levels of parental demands. As younger children require more care than older ones, these demands decrease as children grow up and eventually become adults themselves (Poggesi et al. 2019). Scholars argue that parental demands significantly increased conflict between work and family (Fu and Shaffer 2001; Kim and Ling 2001; Luk and Shaffer 2005; Michel et al. 2011). In the current COVID-19 pandemic, Schieman et al. (2021) found that families with school-going children aged 6-12 experienced the highest levels of work-life conflict, due to intermittent school closures that required parents to put in place alternative care and work arrangements at short notice. It is thus important to study the effects of parental demands in the context of WFC, especially since the pandemic seems to have increased these demands.

Women, more than men, were found to be tied to family commitments due to traditional social norms and expectations (Bielby and Bielby 1989; Nasurdin and Hsia 2008). In this regard, family support was likely to have had considerable influence on how they managed their roles. Previous studies have empirically validated two types of family support, namely (a) emotional support, and (b) instrumental assistance. Emotional support is portrayed as the display of sympathetic, loving and caring behaviors, while instrumental assistance is the rendering of actual and active assistance towards the completion of tasks (King et al. 1995). Findings from Blanch and Aluja (2009) and Nasurdin and O'Driscoll (2012) consistently indicated family support as a key factor in allaying WFC and FIW, respectively. In the local context, Kim and Ling (2001) studied women entrepreneurs in Singapore and found that spousal emotional support and instrumental assistance in child- 
care and housework were associated with lower conflict levels. With its relevance in the local Singapore context, it is essential to include family support in the study of WFC during the pandemic.

\subsection{Research Questions}

The literature presents a few areas that can be explored, and we seek to answer the following research questions. Firstly, how does the COVID-19 pandemic affect WFC, namely WIF and FIW, for working mothers in Singapore? Next, how do work and family factors predict WIF and FIW during COVID-19? Are there any spillover effects between work and family domains? Figure 1 below provides a visual representation of our research questions.



Figure 1. Research model.

\section{Materials and Methods}

\subsection{Sample}

A sample of 754 women who were working and married with children was polled. Respondents' ages ranged from 24 to 75 years, with a mean of 44.29 years. Other basic demographic information relevant to the study is shown in Table 1.

Table 1. Demographic information.

\begin{tabular}{ccc}
\hline & $\%$ & $n$ \\
\hline Race/Ethnicity & & 618 \\
Chinese & 82.0 & 81 \\
Malay & 10.7 & 55 \\
Indian and Others & 7.3 & 289 \\
Age of respondents' children & 38.3 & 213 \\
Under the age of 7 years & 28.2 & 75 \\
Ages 7 to 16 years & 9.9 & 177 \\
Ages 17 to 20 years & 23.5 & \\
Ages 21 years and above &
\end{tabular}

Note: \% based on $n=754$ respondents.

\subsection{Procedure}

An online survey invite was sent to respondents registered with a local Singapore panel, HappyDot.sg (accessed on 17 November 2021). We chose to use HappyDot.sg as all registered panelists were individually verified through courier services to be citizens or permanent residents of Singapore, and their age, gender and race information were ascertained to match their national identity card (HappyDot.sg 2021). HappyDot.sg's practice of physically verifying the identity of respondents at the registration stage mitigates the incidence of "fraudulent" respondents, which Jones et al. (2015) described as those who falsely answer screening questions in order to qualify for surveys. 
The survey invites were sent via email, and data collection lasted for a week in August 2021. Responses that failed attention checks inserted into the survey-to ensure data quality-were removed prior to analysis $(n=45)$. Out of 799 completed surveys, 754 were usable for analysis.

\subsection{Measures}

The survey questionnaire had a total of 27 items across 4 subsections. The WFC subsection had 10 items. With the exception of parental demands (under "family factors"), items for all other measures described were rated on a seven-point Likert-type scale $(1=$ "Strongly disagree" to $7=$ "Strongly agree"). We used the seven-point scale as it was recommended for its greater accuracy and ease of use (Taherdoost 2019).

\subsubsection{Work-Family Conflict (WFC)}

WFC was measured with a scale from Netemeyer et al. (1996), which consisted of 10 items that measured two directions of Work-Family conflict. Five out of the 10 items measured WIF, while the other 5 measured FIW. Some examples of the items used to assess WIF are "The demands of my work interfere with my home and family life" and "The amount of time my job takes up makes it difficult to fulfill family responsibilities". Examples of items used to assess FIW are "I have to put off doing things at work because of demands on my time at home" and "Family-related strain interferes with my ability to perform job-related duties". WIF and FIW had good reliability with a Cronbach's alpha of 0.93 and 0.91 , respectively.

\subsubsection{Work Factors}

The work factors subsection had 5 items for work occupational commitment and 3 items for work role overload. Work occupational commitment was measured with the 5-item Occupational role commitment subscale from Amatea et al.'s (1986) Life Role Salience Scales. Minor adaptation to expand the concept of a "career" to include one's "job" was made. Examples of items used are "I value being involved in a job/career and expect to devote the time and effort needed to develop it" and "I expect to make as many sacrifices as are necessary in order to advance in my work/career". Work occupational commitment had good reliability with a Cronbach's alpha of 0.70 .

Work role overload utilized the 3-item subscale from Beehr et al. (1976). As the phrasing of the items was found to still be relevant in today's work context, no changes were required. A sample of an item is "It often seems like I have too much work for one person to do". Work role overload had good reliability with a Cronbach's alpha of 0.71 .

\subsubsection{Family Factors}

The family factors subsection had 8 items for family support and parental demands and was coded based on the ages of respondents' children-in accordance with the framework by Bedeian et al. (1988). Luk and Shaffer (2005) found this method of coding for parental demands to be useful in predicting Work-Family conflict levels, especially in the Asian context. The categories were operationalized to align with Singapore's education levels. As this sample involved only those already with children, respondents were divided into 4 groups: (1) one or more children over 21 but none under 21; (2) one or more children between 17 and 20 but none under 17; (3) one or more children between 7 and 16 but none under 7; and (4) one or more children under 7.

Family support was measured with King et al.'s (1995) Family Support Inventory for Workers. Due to the substantial length of the full measure, we used 4 items (with the highest item-total correlations) from the emotional sustenance and instrumental assistance dimensions. Examples of items measuring emotional sustenance are "When I have a problem at work, members of my family/my spouse express concern" and "My spouse/family members are sympathetic when I'm upset about my work"; for instrumental assistance, these are "Too much of my time at home is spent picking up after my family 
members/spouse" and "My spouse/family members do their fair share of household chores". Family support had good reliability with a Cronbach's alpha of 0.85 .

\subsubsection{Impact of COVID-19}

The negative impacts of COVID-19 were measured with a single item, "The COVID-19 situation has made balancing work and family life more difficult for me". As opposed to equating balance to equal involvement, effectiveness and satisfaction in both roles, Greenhaus and Allen (2011, p. 174) define "work-family balance" to instead center around feeling "highly effective and satisfied in a role or roles that are of highest priority".

This definition takes into account individual differences in values and interests. Having greater satisfaction in the work domain than in the family domain may not indicate a lack of balance if one prioritizes work more than family, or vice versa. In other words, the COVID-19 item measures not whether the equal management of roles is more difficult, but rather, whether effectiveness and satisfaction in both roles is more difficult as a result of the pandemic.

\section{Results}

To study WFC in the Singapore context, we first conducted an exploratory factor analysis with the WFC scale items by Netemeyer et al. (1996). This helped us determine which items from the WFC scale were suitable for measuring WIF and FIW. Prior to extraction of factors, parallel analysis was conducted, determining the extraction of a two-factor solution. We used principal axis factoring to extract two factors (Kaiser-MeyerOlkin value $=0.95, p<0.001$ ). Table 2 shows that all loadings for each of the factors were above 0.7 . Each factor had 5 out of the 10 items that loaded strongly, and indicated that all scale items were relevant in measuring each of the two factors. The original scale by Netemeyer et al. (1996) found five items that measured WIF and FIW each, and the current factor analysis results also found the same five items that loaded for both factors. From the factor analysis, we are now confident that the WFC scale is adequate in its measurement of WIF and FIW in the Singapore context, and can therefore be used for further analyses in our regression models.

Table 2. Factor analysis of Work-Family conflict.

\begin{tabular}{cc}
\hline Item & Factor \\
\cline { 2 - 2 } The demands of my work interfere with my home and family life. & $\mathbf{1}$ \\
The amount of time my job takes up makes it difficult to fulfil family responsibilities. & 0.88 \\
Things I want to do at home do not get done because of the demands my job puts on me. & 0.92 \\
My job produces strain that makes it difficult to fulfil family duties. & 0.89 \\
Due to work-related duties, I have to make changes to my plans for family activities. & 0.88 \\
The demands of my family or spouse/partner interfere with work-related activities. & 0.73 \\
I have to put off doing things at work because of demands on my time at home. & 0.86 \\
Things I want to do at work do not get done because of the demands of my family or spouse/partner. \\
My home life interferes with my responsibilities at work such as getting to work on time, accomplishing \\
daily tasks, and working overtime.
\end{tabular}

After factor analysis was conducted, composite scores were calculated for all variables of interest, with the exception of the variable "Impact of COVID-19", which was a singleitem measure. Items that loaded onto WIF and FIW, the two dependent variables gleaned from the factor analysis conducted earlier, were also used to calculate composite scores. Table 3 shows the descriptive statistics for study variables. In general, WIF levels $(\mathrm{M}=4.36$, $\mathrm{SD}=1.45)$ were greater than FIW levels $(\mathrm{M}=3.91, \mathrm{SD}=1.38)$. 
Table 3. Descriptive statistics.

\begin{tabular}{ccccc}
\hline Variable & Mean & SD & Min. & Max. \\
\hline $\begin{array}{c}\text { Dependent variable } \\
\text { Work interfering with Family }\end{array}$ & 4.36 & 1.45 & 1 & 7 \\
$\begin{array}{c}\text { Family interfering with Work } \\
\text { Independent variable }\end{array}$ & 3.91 & 1.38 & 1 & 7 \\
COVID-19 impact & 4.26 & 1.60 & 1 & 7 \\
Work occupational & 4.17 & .92 & 1 & 7 \\
$\quad$ commitment & 4.12 & 1.16 & 1 & 7 \\
Work role overload & 2.81 & 1.18 & 1 & 4 \\
Parental demands & 4.45 & 1.07 & 1 & 7 \\
Family support & & & \\
\hline
\end{tabular}

Note: With the exception of parental demands (4-point scale), the rest are on a 7-point scale.

Using the statistical software SPSS v23, linear regression analyses were conducted. Independent predictor variables were entered into the regression model in two blocks: the first was for impact of COVID-19, and the second was for all work and family factors related to WFC (i.e., Work occupational commitment, Work role overload, Parental demands, and Family support). WIF was entered as a dependent variable. A separate regression model was replicated with the same predictor variables but with FIW as the dependent variable. Table 4 displays the correlations between these variables.

Table 4. Intercorrelations among main variables.

\begin{tabular}{|c|c|c|c|c|c|c|c|}
\hline & 1 & 2 & 3 & 4 & 5 & 6 & 7 \\
\hline 1. Work interfering with family & 1.00 & & & & & & \\
\hline 2. Family interfering with work & $0.74^{* * *}$ & 1.00 & & & & & \\
\hline 3. COVID-19 impact & $0.40^{* * *}$ & $0.37 * * *$ & 1.00 & & & & \\
\hline 4. Work occupational commitment & $0.21^{* * *}$ & $0.20 * * *$ & $0.13^{* * *}$ & 1.00 & & & \\
\hline 5. Work role overload & $0.60 * * *$ & $0.41^{* * *}$ & $0.31^{* * *}$ & $0.17^{* * *}$ & 1.00 & & \\
\hline 6. Parental demands & $0.24^{* * *}$ & $0.24^{* * *}$ & $0.11^{* *}$ & $0.11^{* *}$ & $0.17^{* * *}$ & 1.00 & \\
\hline 7. Family support & $-0.19^{* * *}$ & $-0.25^{* * *}$ & $-0.13^{* * *}$ & -0.01 & $-0.18^{* * *}$ & 0.01 & 1.00 \\
\hline
\end{tabular}

Note: ${ }^{* *} p<0.01 ; * * * 0.001$

We checked for independence of errors and collinearity before hypotheses were tested. The variance inflation factor (VIF) of the independent predictor variables in the regression models were all below 2, with the highest VIF at 1.17. The Durbin-Watson statistic was used to ascertain independence of errors, with a value of 1.99 for the WIF model and 2.10 for the FIW model.

Table 5 shows regression coefficients for each of the predictor variables. In model 1 , the impact of COVID-19 has an explained variance of $16 \%$ for $\mathrm{WIF}(\mathrm{B}=0.20, p<0.001)$ and $14 \%$ for FIW $(B=0.21, p<0.001)$, and answers our first research question, confirming that COVID-19 increases WFC. The remaining independent predictor variables were entered into model 2 together. For effects on WIF, Work occupational commitment $(\mathrm{B}=0.13$, $p<0.001)$, Work role overload $(B=0.60, p<0.001)$, Parental demands $(B=0.15, p<0.001)$, and Family support $(\mathrm{B}=-0.11, p<0.01)$ explained a total variance of $27 \%$. For effects on FIW, Work occupational commitment $(\mathrm{B}=0.16, p<0.001)$, Work role overload $(\mathrm{B}=0.31$, $p<0.001)$, Parental demands $(B=0.19, p<0.001)$, and Family support $(\mathrm{B}=-0.22, p<0.01)$ explained a total variance of $16 \%$. The variance that each block of predictors explains for the WIF and FIW models answers our second research question as work and family factors continue to be relevant in explaining WFC; Work occupational commitment, Work role overload, and Parental demands increase WIF and FIW, while Family support decreases both WIF and FIW. 
Table 5. Hierarchical linear regression results for Work interfering with Family (WIF) and Family interfering with Work (FIW).

\begin{tabular}{|c|c|c|c|c|c|c|c|c|}
\hline & \multicolumn{4}{|c|}{ Model 1} & \multicolumn{4}{|c|}{ Model 2} \\
\hline & \multicolumn{2}{|c|}{ WIF } & \multicolumn{2}{|c|}{ FIW } & \multicolumn{2}{|c|}{ WIF } & \multicolumn{2}{|c|}{ FIW } \\
\hline & B & SE & B & SE & B & SE & B & SE \\
\hline Constant & 0.54 & 0.30 & $0.32 * * *$ & 0.32 & & & & \\
\hline COVID-19 impact & $0.20^{* * *}$ & 0.03 & $0.21^{* * *}$ & 0.03 & & & & \\
\hline $\begin{array}{l}\text { Work occupational } \\
\text { commitment }\end{array}$ & & & & & $0.13^{* *}$ & 0.04 & $0.16^{* * *}$ & 0.05 \\
\hline Work role overload & & & & & $0.6^{* * *}$ & 0.04 & $0.31^{* * *}$ & 0.04 \\
\hline Parental demands & & & & & $0.15^{* * *}$ & 0.03 & $0.19^{* * *}$ & 0.04 \\
\hline Family support & & & & & $-0.11^{* *}$ & 0.04 & $-0.22^{* * *}$ & 0.04 \\
\hline Adjusted $\mathrm{R}^{2}$ & \multicolumn{2}{|c|}{0.16} & \multicolumn{2}{|c|}{0.14} & & & \multicolumn{2}{|c|}{0.29} \\
\hline
\end{tabular}

Note: ${ }^{* *} p<0.01 ; * * *<0.001$.

\section{Discussion}

\subsection{Impact of COVID-19 on WFC}

As evidenced in this study, the negative impacts of COVID-19 are associated with higher WFC levels. For each unit increase in negative impacts of COVID-19, WFC increases by 0.20 and 0.21 units for WIF and FIW, respectively. These findings have implications for the study of WFC. For one, our research highlights that the study of WFC has to extend beyond its primary focus on work and family factors to include other considerations such as environmental factors (i.e., impact of COVID-19). Confining the research parameters to work and family factors limits the total variance that could better explain the WFC phenomenon. For example, Blanch and Aluja (2009) studied the interactions between one's personality and Work-Family factors and their effects on WFC, and found moderation effects of personality on FIW conflict. Similarly, in a study of Singaporean women, Aryee (1992, p. 833) found a "modest amount of variance explained" in three areas of WIF (job-spouse, job-parent, and job-homemaker conflict) despite including a wide range of work and family factors. He discussed the possibility that "the source of Work-Family conflict may more appropriately be located in the sociocultural context within which women as well as men experience their lives". It is therefore necessary to look into the wider societal environment as potential predictors for a more holistic comprehension of WFC. Thus, our study underscores the importance for future research to move in that direction.

Many parents have had to increase their parental supervision of children attending online classes from home. Schieman et al. (2021) found that parental demands led to greater WFC in the COVID-19 situation, especially for those with school-going children. In Singapore, schools have introduced more online, home-based learning due to the pandemic, and it increased parental demands to create a conducive learning environment for their children at home. This shift in family arrangements and its potential conflict with work responsibilities sheds light on much-needed support. Cheng et al. (2020) found a general decline in mental health during the pandemic, and Huebener et al. (2021) found women, particularly those with young children, to have lower levers of well-being. Singaporean workers were also found to have less access to flexible work options (Sandberg et al. 2012). Thus, workplace programs for employees' physical and mental well-being should acknowledge such developments and move toward allowing greater flexibility for workers who balance multiple roles. Such flexibility would allow working mothers to temporarily step away from work duties to attend to their children when necessary.

Work and family factors were also found to have cross-domain spillover effects. For example, we found that both the work factors (i.e., work occupational commitment, work role overload) increased WIF as well as FIW conflict levels. Similarly, both of our family factors also influenced FIW and WIF conflict levels (parental demands increased FIW and WIF, while family support reduced FIW and WIF). As working mothers now 
have to contend with the challenges that COVID-19 presents, these spillover effects suggest that the pandemic has blurred the traditional boundaries between work and family. Laumer and Maier (2021) mentioned that distractions arise when physical spaces from both domains are mixed. These observed spillover effects also corroborate findings from Poggesi et al. (2019) and Luk and Shaffer (2005), and suggest that the source of the conflict can induce both types of WFC. In other words, work factors cannot be assumed as the only sources for WIF conflict, and similarly, family factors cannot be considered as the only factors causing FIW conflict. As the COVID-19 pandemic drags on, the mixing of work and family boundaries appears to be an emerging new norm. Policy makers should hence go beyond the traditional thinking that views work and family as separate domains. Rather, future policies should enact changes that can sufficiently address both fronts together.

This is especially so in many developed countries, such as Singapore, where the birth rate is low (Jones 2012). Research has found associations between WFC and childbirth. For example, Bulanda and Lippmann (2012) found that delaying childbirth results in less conflict for working mothers. This could be a potential area for follow-up studies on how environmental factors such as COVID-19 can have a knock-on effect on birth rates.

\subsection{Impact of Work and Family Factors on WFC}

Aside from COVID-19, the study also adds to the current literature in two ways. Firstly, findings confirm the continued relevance of the two main sources of conflict: work and family factors. In our study, work factors such as work occupational commitment and work role overload increased WFC levels; family factors such as parental demands increased WFC levels, while family support decreased WFC levels. Our results are in line with those conducted in Singapore by Aryee (1992) and Kim and Ling (2001). They also corroborate findings from studies carried out in other countries such as Malaysia and New Zealand (Nasurdin and O'Driscoll 2012), Italy (Poggesi et al. 2019), and South Korea (Lee and Lee 2021). While it is not a surprising finding that these factors remain relevant as sources of conflict during the ongoing pandemic, it accentuated an even greater imperative to implement immediate solutions to reduce and mitigate the effects of WFC. Kim and Ling (2001) recommended that having greater spouse support is needed to alleviate WFC, which is of greater relevance now as many employees are working from home and at the same time supervising their children.

Secondly, our results on Singaporean working women provide another case analysis of WFC in the Asian context. Nasurdin and O'Driscoll (2012) looked at a sample of academics in Malaysia and New Zealand and found that work role overload was the most prominent work factor that significantly increased WFC levels. Hassan et al. (2010) found that WIF conflict levels were higher than FIW conflict levels in Malaysia and Western countries. In Singapore, our current study echoes these findings, where work role overload is the single largest predictor for WFC. WIF conflict levels are also significantly higher than FIW conflict levels, suggesting that work factors, in particular work role overload, transcend physical boundaries and potential cultural influences.

\subsection{Study Limitations and Future Research Considerations}

There are some limitations to this study. Firstly, this study was an exploratory piece to examine WFC in the context of COVID-19. However, as COVID-19 impacts were broadly measured with a single item, more exploration can be carried out to understand the types of negative impacts of COVID-19 and what these entail. Secondly, this study was conducted with married, working mothers in Singapore as the primary target audience. As WFC may differ across cultural contexts (Thein et al. 2010), future studies can look into replicating the study in other countries and for other target samples (e.g., fathers). Thirdly, our study only explored COVID-19 as one type of environmental factor in affecting WFC. More environmental factors need to be taken into consideration. For example, recent research suggests that COVID-19 exacerbates gender disparities and inequalities, with more women exiting the workforce or being disproportionately burdened with caregiv- 
ing duties (Chen and Bougie 2020; Landivar et al. 2020; McLaren et al. 2020; Power 2020; Seck et al. 2021; Shockley et al. 2021). Furthermore, given there has been research on other factors such as work role conflict, work role ambiguity, family role conflict, and family role ambiguity, future research should explore how these factors play into the dynamics between work and family during COVID-19.

\section{Conclusions}

This study showed that COVID-19, along with work and family factors, predict WFC levels. Our results provide valuable information that can guide future research. For example, much of the current WFC literature focuses on work and family factors, and more environmental factors such as the COVID-19 situation can be examined in the future.

Author Contributions: Conceptualization, methodology and formal analysis, L.S.N., J.Y.C.T., and T.W.Y.C.; writing-original draft preparation, J.Y.C.T.; writing-review and editing, L.S.N. and T.W.Y.C. All authors have read and agreed to the published version of the manuscript.

Funding: This research study and the APC was funded by RySense Ltd., Singapore. This research received no external funding.

Institutional Review Board Statement: Not applicable.

Informed Consent Statement: Informed consent was obtained from all subjects involved in the study.

Data Availability Statement: Restrictions apply to the availability of these data. Data was obtained from RySense Ltd and are available from the authors with the permission of RySense Ltd.

Acknowledgments: The authors would like to acknowledge the quantitative research and operational teams in RySense that provided support in conducting this study.

Conflicts of Interest: The authors declare no conflict of interest.

\section{References}

Acar, Ahmet. 2020. Effects of COVID-19 crisis on employment and working arrangements. In Reflections on the Pandemics. Edited by Muzaffer Seker, Ali Ozer and Cem Korkut. Ankara: Turkish Academy of Sciences, pp. 463-88.

Adams, Gary, Linda A. King, and Daniel W. King. 1996. Relationships of job and family involvement, family social support, and Work-Family conflict with job and life satisfaction. Journal of Applied Psychology 81: 411-20. [CrossRef]

Ahmad, Aminah. 2010. Work-Family conflict among junior physicians: Its mediating role in the relationship between role overload and emotional exhaustion. Journal of Social Sciences 6: 265-71. [CrossRef]

Ahmad, Sariati, and Martin Skitmore. 2003. Work-family conflict: A survey of Singaporean workers. Singapore Management Review 25: 35-52.

Amatea, Ellen S., E. Gail Cross, Jack E. Clark, and Carol L. Bobby. 1986. Assessing the work and family role expectations of career-oriented men and women: The life role salience scales. Journal of Marriage and the Family 48: 831-38. [CrossRef]

Aryee, Samuel. 1992. Antecedents and outcomes of work-family conflict among married professional women: Evidence from Singapore. Human Relations 45: 813-37. [CrossRef]

Aryee, Samuel. 1993. Dual-earner couples in Singapore: An examination of work and nonwork sources of their experienced burnout. Human Relations 46: 1441-68. [CrossRef]

Bacharach, Samuel B., Peter Bamberger, and Sharon Conley. 1991. Work-home conflict among nurses and engineers: Mediating the impact of role stress on burnout and satisfaction at work. Journal of Organizational Behavior 12: 39-53. [CrossRef]

Baert, Stijn, Louis Lippens, Eline Moens, Johannes Weytjens, and Philippe Sterkens. 2020. The COVID-19 Crisis and Telework: A Research Survey on Experiences, Expectations and Hopes. Bonn: Institute of Labor Economics.

Bedeian, Arthur G., Beverly G. Burke, and Richard G. Moffett. 1988. Outcomes of work-family conflict among married male and female professionals. Journal of Management 14: 475-91. [CrossRef]

Beehr, Terry A., Jeffrey T. Walsh, and Thomas D. Taber. 1976. Relationships of stress to individually and organizationally valued states: Higher order needs as a moderator. Journal of Applied Psychology 61: 41-47. [CrossRef]

Bielby, William T., and Denise D. Bielby. 1989. Family ties: Balancing commitments to work and family in dual earner households. American Sociological Review 54: 776-89. [CrossRef]

Blanch, Angel, and Anton Aluja. 2009. Work, family and personality: A study of work-family conflict. Personality and Individual Differences 46: 520-24. [CrossRef]

Bulanda, Ronald E., and Stephen Lippmann. 2012. The Timing of Childbirth and Family-to-Work Conflict. Sociological Focus 45: 185-202. [CrossRef] 
Byron, Kristin. 2005. A meta-analytic review of work-family conflict and its antecedents. Journal of Vocational Behavior 67: 169-98. [CrossRef]

Cardenas, R. A., D. A. Major, and K. H. Bernas. 2004. Exploring work and family distractions: Antecedents and outcomes. International Journal of Stress Management 11: 346-365. [CrossRef]

Carlson, Dawn S., K. Michele Kacmar, and Larry L. Williams. 2000. Construction and initial validation of a multidimensional measure of Work-Family conflict. Journal of Vocational Behavior 56: 249-76. [CrossRef]

Chen, Innie, and Olga Bougie. 2020. Women's issues in pandemic times: How COVID-19 has exacerbated gender inequities for women in Canada and around the world. Journal of Obstetrics and Gynaecology Canada 42: 1458-59. [CrossRef]

Chen, Jacinta I-Pei, Jason Chin-Huat Yap, Li Yang Hsu, and Yik Ying Teo. 2020. COVID-19 and Singapore: From Early Response to Circuit Breaker. Annals of the Academy of Medicine 49: 561-72. [CrossRef]

Cheng, Terence C., Seonghoon Kim, and Kanghyock Koh. 2020. The Impact of COVID-19 on Subjective Well-Being: Evidence from Singapore. Bonn: Institute of Labor Economics.

Chung, Gerard, Xi Wen Chan, Paul Lanier, and Peace W. Y. Ju. 2020. Associations between work-family balance, parenting stress, and marital conflicts during COVID-19 pandemic in Singapore. OSF Preprints. [CrossRef]

Chung, Heejung, Holly Birkett, Sarah Forbes, and Hyojin Seo. 2021. COVID-19, flexible working, and implications for gender equality in the United Kingdom. Gender \& Society 35: 218-32. [CrossRef]

Fisher, Jenny, Jean-Charles Languilaire, Rebecca Lawthom, Rense Nieuwenhuis, Richard J. Petts, Katherine Runswick-Cole, and Mara A. Yerkes. 2020. Community, work, and family in times of COVID-19. Community, Work and Family 23: 247-52. [CrossRef]

Foley, Sharon, Hang-yue Ngom, and Steven Lui. 2005. The effects of work stressors, perceived organizational support, and gender on work-family conflict in Hong Kong. Asia Pacific Journal of Manage 22: 237-56. [CrossRef]

Forbes, Sarah, Holly Birkett, Lowri Evans, Heejung Chung, and Julie Whiteman. 2020. Managing Employees during the COVID19 Pandemic: Flexible Working and the Future of Work. United Kingdom Equal Parenting Project. Available online: https: //www.birmingham.ac.uk/schools/business/research/research-projects/equal-parenting/research.aspx (accessed on 6 October 2021).

Frone, Michael R., John K. Yardley, and Karen S. Markel. 1997. Developing and testing an integrative model of the Work-Family interface. Journal of Vocational Behavior 50: 145-67. [CrossRef]

Fu, Carmen K., and Margaret A. Shaffer. 2001. The tug of work and family: Direct and indirect domain-specific determinants of Work-Family conflict. Personnel Review 30: 502-22. [CrossRef]

Galovan, Adam M., Tamara Fackrell, Lydia Buswell, Blake L. Jones, E. Jeffrey Hill, and Sarah June Carroll. 2010. The work-family interface in the United States and Singapore: Conflict across cultures. Journal of Family Psychology 24: 646-56. [CrossRef]

Goldscheider, Frances, Eva Bernhardt, and Trude Lappegård. 2015. The Gender Revolution: A Framework for Understanding Changing Family and Demographic Behavior. Population and Development Review 41: 207-39. [CrossRef]

González, María José, Teresa Jurado-Guerrero, and Manuela Naldini. 2009. What Made Him Change? An Individual and National Analysis of Men's Participation in Housework in 26 Countries. DemoSoc Working Paper 30. Barcelona: Universitat Pompeu Fabra.

Greenhaus, Jeffrey H., and Tammy D. Allen. 2011. Work-Family balance: A review and extension of the literature. In Handbook of Occupational Health Psychology, 2nd ed. Edited by Lois E. Tetrick and James Campbell Quick. Washington: American Psychological Association, pp. 165-83.

Greenhaus, Jeffrey H., and Nicholas J. Beutell. 1985. Sources and conflict between work and family roles. The Academy of Management Review 10: 76-88. [CrossRef]

Guille, Constance, Elena Frank, Zhuo Zhao, David A. Kalmbach, Paul J. Nietert, Douglas A. Mata, and Srijan Sen. 2017. Work-family conflict and the sex difference in depression among training physicians. JAMA Internal Medicine 177: 1766-72. [CrossRef]

HappyDot.sg. 2021. What Singapore Thinks. Available online: https:/ / www.happydot.sg/ (accessed on 17 November 2021).

Haque, M. Shamsul. 2000. Representation of women in governance in Singapore: Trends and problems. Asian Journal of Political Science 8: 59-87. [CrossRef]

Hassan, Zaiton, Maureen F. Dollard, and Anthony H. Winefield. 2010. Work-family conflict in East vs. Western countries. Cross Cultural Management: An International Journal 17: 30-49. [CrossRef]

Huebener, Mathias, Sevrin Waights, C. Katharina Spiess, Nico A. Siegel, and Gert G. Wagner. 2021. Parental well-being in times of COVID-19 in Germany. Review of Economics of the Household 19: 91-122. [CrossRef]

Huffman, Ann H., Kristine J. Olson, Thomas C. O'Gara Jr., and Eden B. King. 2014. Gender role beliefs and fathers' work-family conflict. Journal of Managerial Psychology 29: 774-93. [CrossRef]

Ingram, Carolyn, Vicky Downey, Mark Roe, Yanbing Chen, Mary Archibald, Kadri-Ann Kallas, Jaspal Kumar, Peter Naughton, Cyril O. Uteh, Alejandro Rojas-Chaves, and et al. 2021. COVID-19 Prevention and Control Measures in Workplace Settings: A Rapid Review and Meta-Analysis. International Journal of Environmental Research and Public Health 18: 7847. [CrossRef] [PubMed]

Irawanto, Dodi W., Khusnul R. Novianti, and Kenny Roz. 2021. Work from Home: Measuring Satisfaction between Work-Life Balance and Work Stress during the COVID-19 Pandemic in Indonesia. Economies 9: 96. [CrossRef]

Jones, Gavin. 2012. Late marriage and low fertility in Singapore: The limits of policy. The Japanese Journal of Population 10: 89-101.

Jones, Michael S., Lisa A. House, and Zhifeng Gao. 2015. Respondent Screening and Revealed Preference Axioms: Testing Quarantining Methods for Enhanced Data Quality in Web Panel Surveys. Public Opinion Quarterly 79: 687-709. [CrossRef] 
Jones, Blake L., Edward J. Hill, and Richard B. Miller. 2020. Family routines and family satisfaction in Singapore: Work-Family fit as a moderator. Asia Pacific Journal of Human Resources 58: 24-45. [CrossRef]

Kahn, Robert L., Donald M. Wolfe, Robert P. Quinn, J. Diedrick Snoek, and Robert A. Rosenthal. 1964. Organizational Stress. New York: Wiley \& Sons.

Kaufman, Gayle, and Hiromi Taniguchi. 2019. Gender equality and Work-Family conflict from a cross-national perspective. International Journal of Comparative Sociology 60: 385-408. [CrossRef]

Kim, Jean Lee Siew, and Choo Seow Ling. 2001. Work-family conflict of women entrepreneurs in Singapore. Women in Management Review 16: 204-21. [CrossRef]

King, Linda A., Laura K. Mattimore, Daniel W. King, and Gary Adams. 1995. Family Support Inventory for Workers: A new measure of perceived social support from family members. Journal of Organizational Behavior 16: 235-58. [CrossRef]

Landivar, Liana Christin, Leah Ruppanner, William J. Scarborough, and Caitlyn Collins. 2020. Early Signs indicate that COVID-19 is exacerbating gender inequality in the labor force. Socius 6: 1-3. [CrossRef]

Laumer, Sven, and Christian Maier. 2021. Why do People (not) Want to Work from Home? An Individual-focused Literature Review on Telework. In Proceedings of the 2021 on Computers and People Research Conference (SIGMIS-CPR'21). New York: Association for Computing Machinery, pp. 41-49. [CrossRef]

Lee, Hayoung, and Soo-Young Lee. 2021. Is More Commitment Always Better? A Study on the Side Effects of Excessive Organizational Commitment on Work-Family Conflict. Review of Public Personnel Administration 41: 25-56. [CrossRef]

Luk, Dora M., and Margaret A. Shaffer. 2005. Work and family domain stressors and support: Within- and cross-domain influences on Work-Family conflict. Journal of Occupational and Organizational Psychology 78: 489-508. [CrossRef]

McIntyre, Roger S., and Yena Lee. 2020. Projected increases in suicide in Canada as a consequence of COVID-19. Psychiatry Research 290: 1-3. [CrossRef] [PubMed]

McLaren, Helen J., Karen R. Wong, Kieu N. Nguyen, and Komalee N. D. Mahamadachchi. 2020. COVID-19 and Women's Triple Burden: Vignettes from Sri Lanka, Malaysia, Vietnam and Australia. Social Sciences 9: 87. [CrossRef]

McLellan, Kristy-Lee, and Koos Uys. 2009. Balancing dual roles in self-employed women: An exploratory study. South African Journal of Industrial Psychology 35. [CrossRef]

Menniti, Adele, Pietro Demurtas, Serena Arima, and Alessandra De Rose. 2015. Housework and Childcare in Italy: A Persistent Case of Gender Inequality. Genus 71: 79-108.

Michel, Jesse S., Lindsey M. Kotrba, Jacqueline K. Mitchelson, Malissa A. Clark, and Boris B. Baltes. 2011. Antecedents of Work-Family conflict: A meta-analytic review. Journal of Organizational Behavior 32: 689-725. [CrossRef]

Nasurdin, Aizzat Mohd, and Khor Lee Hsia. 2008. The influence of support at work and home on work-family conflict: Does gender make a difference? Research and Practice in Human Resource Management 16: 14.

Nasurdin, Aizzat Mohd, and Michael P. O'Driscoll. 2012. Work overload, parental demand, perceived organizational support, family support, and work-family conflict among New Zealand and Malaysian academics. New Zealand Journal of Psychology 41: 38-48.

Netemeyer, Richard G., James Boles, and Robert C. McMurrian. 1996. Development and validation of Work-Family conflict and family-work conflict scales. Journal of Applied Psychology 81: 400-10. [CrossRef]

Poggesi, Sara, Michela Mari, and Luisa De Vita. 2019. Women entrepreneurs and work-family conflict: An analysis of the antecedents. International Entrepreneurship and Management Journal 15: 431-54. [CrossRef]

Power, Kate. 2020. The COVID-19 pandemic has increased the care burden of women and families. Sustainability: Science, Practice and Policy 16: 67-73. [CrossRef]

Rau, Barbara L., and Maryanne M. Hyland. 2002. Role conflict and flexible work arrangements: The effects on applicant attraction. Personnel Psychology 55: 111-36. [CrossRef]

Sakamoto, Haruka, Masahiro Ishikane, Cyrus Ghaznavi, and Peter Ueda. 2021. Assessment of suicide in Japan during the COVID-19 pandemic vs. previous years. JAMA Network Open 4. [CrossRef]

Sandberg, Jonathan G., Jeremy B. Yorgason, Richard B. Miller, and E. Jeffrey Hill. 2012. Family-to-Work Spillover in Singapore: Marital Distress, Physical and Mental Health, and Work Satisfaction. Family Relations 61: 1-15. [CrossRef]

Schieman, Scott, Philip J. Badawy, Melissa A. Milkie, and Alex Bierman. 2021. Work-life conflict during the COVID-19 pandemic. Socius 7: 1-19. [CrossRef]

Seck, Papa A., Jessamyn O. Encarnacion, Cecilia Tinonin, and Sara Duerto-Valero. 2021. Gendered impacts of COVID-19 in Asia and the Pacific: Early evidence on deepening socioeconomic inequalities in paid and unpaid work. Feminist Economics 27: 117-32. [CrossRef]

Sher, Leo. 2020. The impact of the COVID-19 pandemic on suicide rates. QJM: An International Journal of Medicine 113: 707-12. [CrossRef]

Shockley, Kristen M., Malissa A. Clark, Hope Dodd, and Eden B. King. 2021. Work-family strategies during COVID-19: Examining gender dynamics among dual-earner couples with young children. Journal of Applied Psychology 106: 15-28. [CrossRef]

Taherdoost, Hamed. 2019. What Is the best response scale for survey and questionnaire design; Review of different lengths of rating scale/attitude, scale/likert scale. International Journal of Academic Research in Management 8: 1-10.

Thein, Htwe Htwe, Siobhan Austen, Jan Currie, and Erica Lewin. 2010. The impact of cultural context on the perception of work/ family balance by professional women in Singapore and Hong Kong. International Journal of Cross Cultural Management 10: 303-20. [CrossRef] 
Voydanoff, Patricia. 2005. Work Demands and Work-to-Family and Family-to-Work Conflict: Direct and Indirect Relationships. Journal of Family Issues 26: 707-26. [CrossRef]

Wang, Peng, John J. Lawler, and Kan Shi. 2010. Work-Family conflict, self-efficacy, job satisfaction, and gender: Evidences from Asia. Journal of Leadership \& Organizational Studies 17: 298-308. [CrossRef]

Weinert, Christoph, Christian Maier, and Sven Laumer. 2015. Why are teleworkers stressed? An empirical analysis of the causes of telework-enabled stress. Wirtschaftsinformatik Proceedings 2015: 94. 